\title{
Effect of propranolol on capsular reaction around silicone implants in guinea pigs ${ }^{1}$
}

\author{
Charles Jean Gomes de MesquitaI, Sérgio Botelho Guimarães ${ }^{\mathrm{II}}$, José Alberto Dias Leite Filho ${ }^{\mathrm{III}}$, Felipe Silva Maciel ${ }^{\mathrm{IV}}$, José Lima \\ de Carvalho Rochav, José Alberto Dias Leite ${ }^{\mathrm{VI}}$
}

DOI: http://dx.doi.org/10.1590/S0102-86502015001000004

${ }^{I} \mathrm{MSc}$, Fellow PhD degree, Postgraduate Program in Surgery, Federal University of Ceara (UFC), Professor of Medicine, Christus Universitary Center (UNICHRISTUS), Fortaleza-CE, Brazil. Conception, design, intellectual and scientific content of the study; acquisition and interpretation of data; manuscript writing.

IIPhD, Associate Professor, Department of Surgery, Head, Experimental Surgical Research Laboratory (LABCEX), UFC, Fortaleza-CE, Brazil. Manuscript writing, critical revision.

IIIFellow Master degree, Postgraduate Program in Surgery, UFC, Fortaleza-CE, Brazil. Technical procedures.

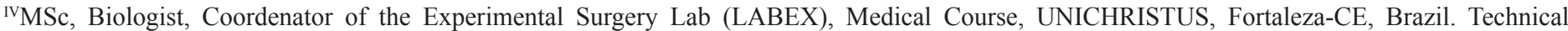
procedures, acquisition of data.

${ }^{\vee}$ MSc, Fellow PhD degree, Postgraduate Program in Surgery, UFC, Fortaleza-CE, Brazil. Acquisition and interpretation of data.

${ }^{v} \mathrm{PhD}$, Full Professor, Head, Orthopedic Surgery Division, UFC, Fortaleza-CE, Brazil. Conception, design, intellectual and scientific content of the study; final approval of the manuscript, critical revision.

\section{ABSTRACT}

PURPOSE: To evaluate the effect of propranolol on capsular architecture around silicone implants by measuring the inflammation, capsular thickness, and collagen fiber density, using a guinea pig experimental model.

METHODS: Thirty six adult male guinea pigs randomly divided into two groups $(n=18)$ were used. Each one received a silicone implant with textured-surface. The capsular tissue around implants from untreated or treated animals with the beta-adrenoceptor antagonist propranolol $(10 \mathrm{mg} / \mathrm{kg}$, dissolved in daily water) were analyzed for inflammation by histological scoring, capsular thickness by computerized histometry, and collagen fibers type I and Type III density by picrosirius polarization at different time points (7, 14 or 21 days after silicone implantation).

RESULTS: Propranolol treatment reduced inflammation and impaired capsular thickness and delayed collagen maturation around the textured implant.

CONCLUSION: Propranolol reduces the risk of developing capsular contracture around silicone implants with textured surface.

Key words: Silicone Elastomers. Implant Capsular Contracture. Collagen. Propranolol. Guinea Pigs. 


\section{Introduction}

Concepts about beauty have increased the demand for breast implants. According to the International Society for Aesthetic Plastic Surgery (ISAPS), over 1.2 million procedures were performed worldwide exclusively for breast augmentation in 2011 ${ }^{1}$. In Brazil, according to the Brazilian Society of Plastic Surgery (SBCP), this number is over 150.000 each year ${ }^{2}$.

Foreign body reaction often interferes with the longterm functionality and performance of implanted biomedical devices through fibrous capsule formation ${ }^{3,4}$. Both the wound healing and immune system have very complex interconnections and implanting biomaterials are likely to affect many of these pathways $^{3-5}$. Despite silicone has being considered relatively inert, as any biomaterial implanted in the human body, its elicits this protective immune-inflammatory reaction from the organism, starting a rejection process that interferes with wound healing process and finish by encapsulating this foreign body too large to be eliminated by phagocytosis ${ }^{6-11}$. Ordinarily beneficial, in some cases such capsules become pathologically active, and undergo an adverse capsular contracture (ACC), leading to swelling, spherical constrictive fibrosis, distortion, hardness and pain in the breast, with physical and psychological distress ${ }^{10-14}$.

Histologically, breast implant capsules have been well characterized. Long time ago it was hypothesized that collagen production and deposition might be increased by inflammation in contracted capsules since there is histological evidence for increased lymphocytes, macrophages and multinuclear giant cells $\mathrm{s}^{6-8,12-14}$. Also, the ratio of collagen type I:type III increases in rigid tissue compared with more distensible ones ${ }^{15}$. The management of ACC is a wellknown problem for plastic surgeons. ACC occurs in 0-74\% of breast implant operations depending on the series, follow-up, implant shell and content, surface texture, presence of subclinical infection or accumulation of tissue fluids in the implant pocket, patient age, surgical technique and anatomical location of implants and others ${ }^{9-16}$.

Just as there is no universally accepted etiology, no single unified hypotheses that explain pathogenesis of ACC have been identified. Nowadays, capsular contracture etiology and its development seem to be multi-factorial ${ }^{13}$. Also, no effective treatments for adverse capsular contractures have been identified. Revision surgery for capsulotomy or capsulectomy with implant exchange are the standard treatments ${ }^{14}$. Unfortunately, these procedures are associated with a high risk of complications, recurrences included ${ }^{11-14}$.

A non-surgical therapy for ACC would be desirable; however, so far, no study has clearly demonstrated their effectiveness. Researchers and surgeons have used antimicrobials agents, steroids, non-steroidal anti-inflammatory drugs, and more recently, leukotriene antagonists to skirmish contracture, with little success and often with collateral effects ${ }^{16-18}$. Propranolol is a non-selective betaadrenoceptor antagonist that have a well recognized antihypertensive and antiarrythmic action and has been widely used in cardiovascular disease, migraine and post-traumatic stress disorder ${ }^{19,20}$. Propranolol now is used as a first-line treatment in infantile hemangiomas when intervention is required ${ }^{19-21}$. Since propranolol's invention by Sir James Black and co-workers in $1960 \mathrm{~s}^{19}$, it has been demonstrated that the peripheral nervous system has important participation in wound healing and that beta-blockers modulates stress-related injury, both wound healing and inflammation, facts that attracted the interest of numerous scholars and led to various hypotheses ${ }^{19-22}$.

Souza et al..$^{22}$ demonstrated that sympathetic denervation accelerates wound contraction but delays reepithelialization in rats. Recently was shown that early propranolol administration to severely injured patients can improve bone marrow dysfunction ${ }^{23}$. There are also interactive effects between polymorphisms in the beta-adrenergic receptors and longitudinal changes in obesity, an inflammatory-stateprone disease ${ }^{24}$. The potential use of propranololol to curb fibrosis conditions, as like ACC, was well demonstrated by another study where beta-adrenoceptor blockade has antifibrotic effects in a murine model of nonsinusoidal liver fibrosis ${ }^{25}$.

Fibrogenesis is a mechanism of wound healing and repair. However, prolonged injury promotes deregulation of normal processes and results in extensive deposition of extracellular matrix (ECM) proteins and fibrosis ${ }^{26}$. Based in these facts and evidences, we hypothesized that propranolol could impairs capsular fibrosis surrounding silicone implants. To test this hypothesis, we conducted an experimental study to evaluate the effect of propranolol on capsular formation by measuring the capsule thickness, scoring inflammation and analyzing deposition of collagen type I and type III using an animal model.

\section{Methods}

This study was conducted at the Experimental Surgery Lab (LABEX), Medical Course, Christus Universitary Center (UNICHRISTUS). The experimental protocol was approved by the Animal Research Ethics Committee of the Federal University of Ceara (UFC). All surgical procedures and animal handling were conducted in accordance with the Brazilian Federal Law No. 11794 of October 8, 2008 (http://www.planalto.gov.br/ccivil_03/_ Ato2007-2010/2008/Lei/L11794.htm).

Thirty-six mature male guinea pigs weighing 520 to $750 \mathrm{~g}$ were used. Animals were maintained in adequate standard 
conditions at the LABEX. Each animal was kept in a standard polypropylene box labeled with information on each animal. These animals were randomly divided in two groups $(n=18)$. In the dorsum of each animal a textured silicone gel-filled mini-prosthesis, with pore size of 0.05-0.25 mm, shell-shaped and round-based, $2.2 \mathrm{~cm}$ in diameter, and volume of two $\mathrm{mL}$ was implanted subcutaneously. All mini-prosthesis were produced and donated by SILIMED ${ }^{\mathrm{TM}}$ Company,São Paulo, Brazil) (Figure 1). A group of 18 animals was administered $10 \mathrm{mg} / \mathrm{kg}$ of propranolol hydrochloride (PROP) orally in $150 \mathrm{ml}$ of daily water. The control group (CTRL)was administered daily the same volume of tap water. Each group of animals was split into three subgroups of six animals Results were evaluated at 7, 14 and 21 days after implantation surgery. Following samples collection the animals were killed by an overdose of anesthetics.

\section{Surgical procedure}

All surgical procedures were performed under general anesthesia by intraperitoneal injection of $100 \mathrm{mg} / \mathrm{kg}$ of ketamine hydrochloride (Vetanarcol ${ }^{\mathrm{TM}}$, $50 \mathrm{mg} / \mathrm{ml}$, König S/A, Sao Paulo, Brazil) associated to $10 \mathrm{mg} / \mathrm{kg}$ of xylazine (KensolTM, $20 \mathrm{mg} / \mathrm{ml}$, König S/A, Sao Paulo, Brazil). Under anesthesia, each animal was placed in the prone position. After epilation of the dorsum from tail up to cervical region, the skin was prepared and draped in a sterile fashion. A surgical transverse incision of $2 \mathrm{~cm}$, symmetrically crossing the midline above lumbar region was done $3-\mathrm{cm}$ above the hind limbs. Following, a tunnel was built above the panniculus carnosus, up to the shoulder blades. The implant (Figure 1) was inserted through the incision and placed on a pocket between scapulas, approximately $3 \mathrm{~cm}$ apart from the incision (Figure 2). Incision was closed using 4-0 polyamide interrupted sutures.

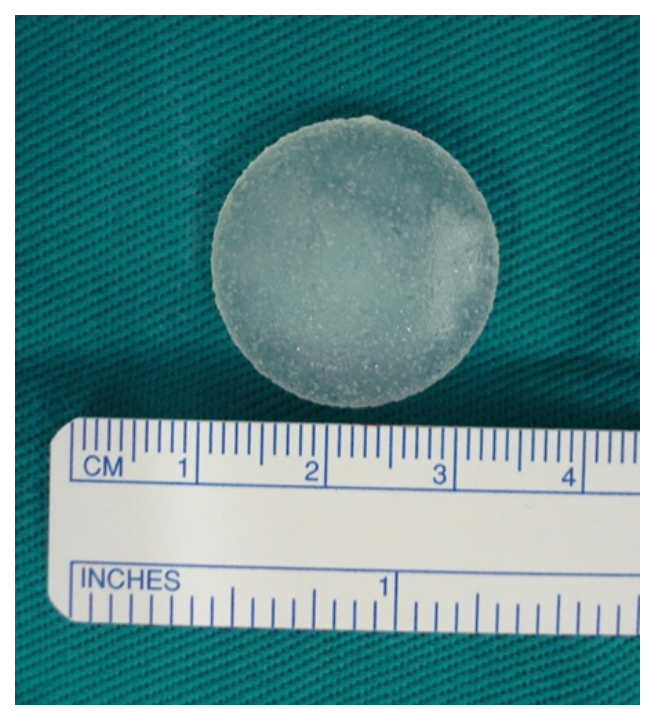

FIGURE 1 - Textured silicone implant.

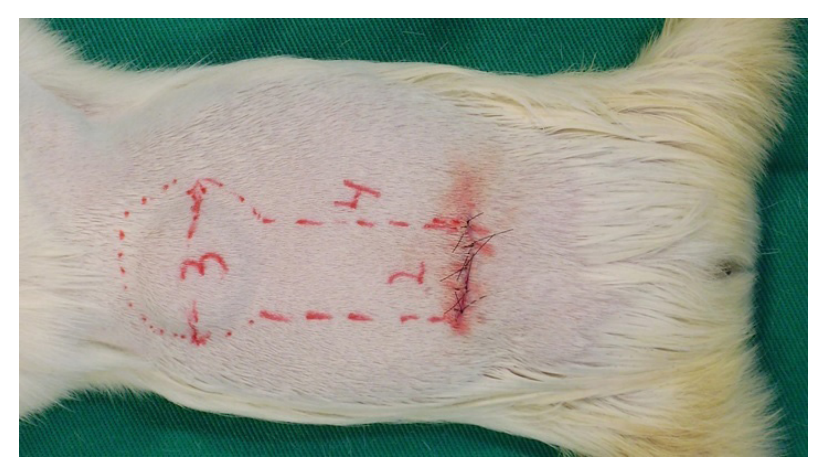

FIGURE 2 - Prosthesis implanted in the animal dorsum.

Follow-up and macroscopic assessment

After surgical procedures, animals were placed on a warm environment at $25^{\circ} \mathrm{C}$ until complete recovering from anesthesia, and afterwards re-allocated to their respective boxes. Animals were daily observed for their level of activity, respiratory distress, diarrhea, starvation or weight gain, and refusal of food of food or water (indirect signals of infection or sepsis). The macroscopic aspects of wound and pocket implant were carefully inspected for dislocation or extrusion of the prostheses, as well for abscess, hematoma, seroma or wound dehiscence.If any sign of suffering was seen, the veterinarian was authorized to interrupt the research and to euthanize the animal.

\section{Microscopic assessment}

The involving skin, subjacent tissues, capsules and implants were removed en bloc and preserved for later qualitativequantitative analysis of histologic samples sectioned 5 to $7 \mu \mathrm{m}$ and stained with hematoxylin-eosin (H\&E) and histochemical Sirius Red dye (SR) saturated with picric acid as described elsewhere ${ }^{27-30}$. SR-stained slides were used to analysis of collagen morphology and deposition under polarization.

\section{Qualitative histologic analysis}

H\&E stained slides were used to establish the type and intensity of inflammation by scoring and to measure capsule thickness. Grading was done by an independent pathologist. Briefly, acute inflammation was characterized by the findings of neutrophyls, polymorphonuclear cells, vascular congestion and diapedesis; as to the chronic inflammatory infiltrate, the presence of mononuclear cells (lymphocytes, plasmocytes and monocytes). As described elsewhere ${ }^{31}$ the two kinds of inflammation were classified by scores $(0=$ absent; $1=$ discrete; $2=$ moderate, and $3=$ intense), three slides / animal. Collected data were used to calculate the average score from each group by timepoint. 


\section{Quantitative analysis of capsule thickness}

H\&E-stained sections were examined by light microscopy. Microscopic digital images were obtained as previously described ${ }^{28}$. The points of greatest thickness were located by scanning the sections at a magnification of $\mathrm{x} 100$, with the selection of three regions of interest (ROIs): a middle point correspondent to maximal thickness and two lateral adjacent points 50 micra apart from the middle point. Each digitized image (640 x 480 pixels) corresponded to a microscope field of $0.29 \mathrm{~mm}^{2}$ (one pixel $=0,53$ micrometer). Digital images were processed and analyzed for capsule thickness using the calibrated free hands measurement tools of the public domain NIH Image J program (developed at the U.S. National Institute of Health, Baltimore-MD, and available at htttp://rsb.info.nih.gov/ nih-image/). Three slides were examined per animal and three ROIs in each section were measured by digital planimetry (total $=54$ observations by subgroup). The averages mean thickness/ capsule/group/ that were measured at that ROIs of capsules were expressed as mean \pm standard deviation (SD).

\section{Quantitative collagen analysis}

New histological sections of 7 micrometers thickness were cut from the paraffin blocks that were utilized for the histopathological study. These sections were taken from the point of greatest capsular thickness from inner layer to outer lamina of tissue. Three slides of three SR-stained samples of the capsular layer of each animal were used to assess morphometry and density of collagen type III - Col 3 (fibrilar, non-polymerized) and type I - Col 1(thick, polymerized) under an optic polarizedlight microscope.

Polarized images $\left(100 \mathrm{X}\right.$, each field area $\left.=0.29 \mathrm{~mm}^{2}\right)$ were captured with a high-resolution digital camera (Sony $^{\mathrm{TM}}$ DSC H-10016.1 MP, Japan) coupled to a polarized microscope. Digitized images were transferred to a personal computer and saved to disc as bmp files (640 x 480 pixels) based on RGB (red, green, blue) color mode, forming an image bank. The computer was equipped with the SAMM, an image analysis software developed and validated by the Federal University of Ceará, Brazil ${ }^{32-33}$. Due to their anisotropic properties, under polarization, collagen type I (thicker and bundled mature collagen fibers) turns red (reddish birrefringence) and collagen type III (fibrilar, thinner and dispersed immature collagen) turns green. Based on the color spectrum, the "separate colors" tool was used to split images into color channels (red, green, blue $)^{28,32}$. in order to analyze by differential colorimetric method the deposition of the collagen fibers. The results were expressed as percentages of areas of collagen type I ( $\mathrm{Col} \mathrm{1)}$ or collagen type III ( $\mathrm{Col} 3$ ) positive pixels per recorded field (the total area of the histologic cut). Subsequently, Col 1/Col 3 ratios were calculated for each group. The average mean percentage for each capsule thin section was determined by calculating the average of means obtained from reading the three ROIs. In our pilot-study, these assessments were performed in two occasions separated by a lapse time of three months by two observers without knowledge of the clinic pathological stage and the results from the histological study using H.E. staining. No significant inter-observer and intra-observer variability has been noticed.

\section{Statistical analysis}

In the descriptive analysis, data were summarized as means, medians, standard deviations, standard errors, $1^{\text {st }}$ and $3^{\text {rd }}$ quartiles, minimum and maximum values. Scores from the histological assessment of inflammation were analyzed with Kruskal-Wallis test with Dunn's multiple comparison tests when necessary. Capsule thickness data were analyzed by one factor analysis of variance (ANOVA). Collagen type I and type III deposition percentage were analyzed with Kruskal-Wallis test with Dunn's multiple comparison tests when necessary. Col 1/Col 3 ratios were analyzed with Sudent's t test. The used statistical programs were: Statistical Package for Social Sciences (SPSS) version 18.0 and GraphPad Prism 5.0. For evaluating normality conditions of the variables the Shapiro-Wilks test was used. Statistical significance was set for a confidence interval of $95 \%(\mathrm{p}<0.05)$.

\section{Results}

\section{Macroscopic analysis}

No infection or mortality was observed during the experiments, and no local complications were clinically detectable. Also, no evidence of inactivity, diarrhea, starvation or weight gain was observed. A thin, well vascularized, and loosely adherent capsule was found surrounding the implant in all animals, independently of the time of harvesting samples (Figure 2). Although difficult to analyze, apparently the capsules from control group were more opaque and adhered to implant than capsules from propranolol-treated group. 


\section{Microscopic analysis}

Capsule morphology and inflammation scores

A tri-laminar structure of the capsule was found in all specimens both in H\&E and picrosirius stained samples. There was an inner cellular layer adjacent to the implant, an intervening lamina comprising loose connective tissue including an internal vascular supply and a rich cellular presence, and an outer layer collagenous layer of densely packed collagen fibres aligned parallel to the prosthese surface. The inner layer exhibited an epitheliallike single layer composed from fibrocytes and histiocytes, the so called synovial-type metaplasia (STM). The STM was less pronounced in propranolol group at $21^{\text {st }}$ post-operative day, although without statistical significance. Also, in some capsules villous hyperplasia was found (Figure 3). Except for the apparent lesser vascularization (not quantified) in the middle layer from propranolol-treated group as compared to controls we did not observed gross differences between capsules.
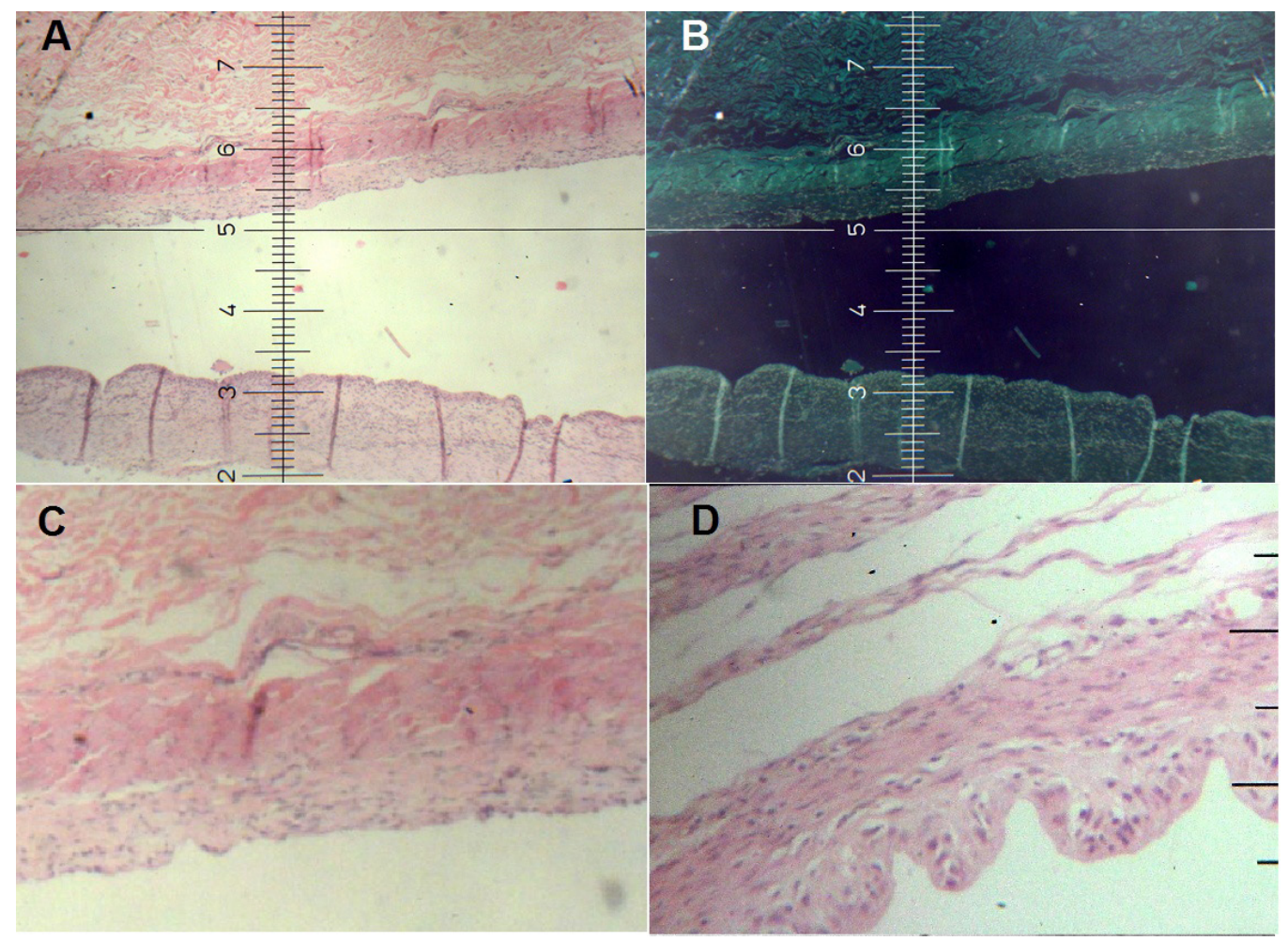

FIGURE 3 - Microscopic images of capsules. (A) Tri-layered structure of capsule. (B) Negative image showing the three layers with bright intervening lamina. (C) Zooming of tri-layered capsule. (D) Synovial-type metaplasia with villous hyperplasia of inner capsular layer (x100).

All capsules tended to become less cellular with time. Propranolol-treated capsules demonstrated less inflammatory acute response moderate/intense in about $70 \%$ of samples at $7^{\text {th }}$ post-operative (PO) day; absente/discrete in about $84 \%$ at $14^{\text {th }}$ PO day, but persistent at $21^{\text {st }}$ day $(33 \%)$, and no giant cells anytime (Table 1). Also, chronic inflammation was absent

TABLE 1 - Intensity of acute inflammatory reaction.

\begin{tabular}{lcccc}
\hline \multirow{2}{*}{ Group } & Acute & \multicolumn{3}{c}{ Post-operative day (\%) } \\
\cline { 3 - 5 } & inflammation & $\mathbf{7}^{\text {th }}$ & $\mathbf{1 4}^{\text {th }}$ & $\mathbf{2 1}^{\text {st }}$ \\
\hline \multirow{2}{*}{ Control } & Absent/Discrete & 33.3 & 66.7 & 83.3 \\
& Moderate/Intense & 66.7 & 33.3 & 16.7 \\
\multirow{2}{*}{ Propranolol } & Absent/Discrete & 33.3 & 83.3 & 66.7 \\
& Moderate/Intense & 66.7 & 16.7 & 33.3 \\
\hline
\end{tabular}

in $100 \%$ of propranolol-treated capsules at $21^{\text {st }} \mathrm{PO}$ day. Acute inflammation was practically resolved by $21^{\text {st }} \mathrm{PO}$ day in the control group. However, $100 \%$ of tissue samples from this group harvested at $21^{\text {st }}$ day exhibited a moderate to intense chronic inflammatory infiltrate, and some sparsely giant cells were found at that moment (Table 2).

TABLE 2 - Intensity of chronic inflammatory reaction.

\begin{tabular}{lcccc}
\hline Group & \multirow{2}{*}{$\begin{array}{c}\text { Chronic } \\
\text { inflammation }\end{array}$} & \multicolumn{2}{c}{ Post-operative day (\%) } \\
\cline { 3 - 5 } & Absent/Discrete & 66.7 & 83.3 & 0.0 \\
\hline \multirow{2}{*}{ Control } & Moderate/Intense & 33.3 & 16.7 & 100 \\
& Absent/Discrete & 83.3 & 66.7 & 83.3 \\
& Mopranolol & $\mathbf{2 1}^{\text {st }}$ & \\
& Moderate/Intense & 16.7 & 33.3 & 16.7 \\
\hline
\end{tabular}




\section{Capsule thickness}

Propranolol was highly effective in reducing capsule thickness at $7^{\text {th }}$ and $21^{\text {st }}$ days periods when compared to control group (Figure 4 and Table 3 ).

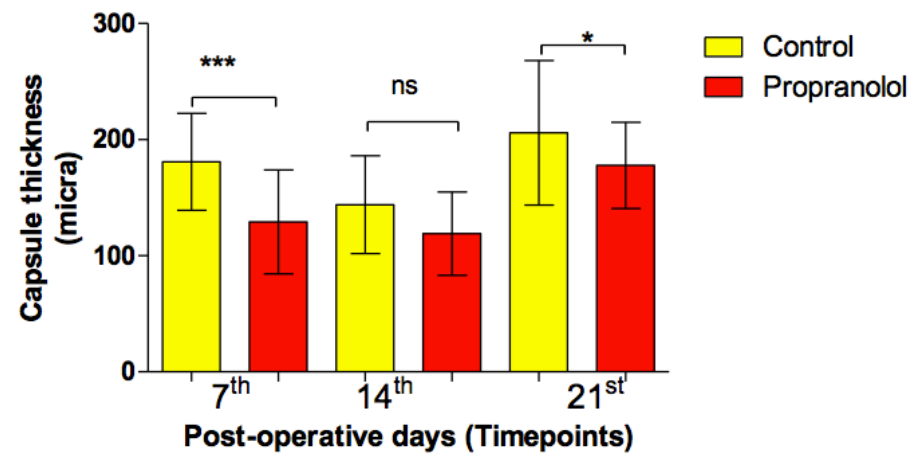

FIGURE 4 - Thickness measures of the capsular reaction Bars represent control and propranalol groups at $7^{\text {th }}, 14^{\text {th }}$ and $21^{\text {st }}$ timepoints. Significant differences were encountered on $7^{\text {th }}$ $(p<0.001)$ and $21^{\text {st }}$ timepoints $(p<0.05)$, when comparing control and propranolol groups. ANOVA test. $\mathrm{ns}=$ non significant.

TABLE 3 - Descriptive statistics of collagen type I deposition.

\begin{tabular}{lcccccc}
\hline & $\begin{array}{c}\text { Ctrl } \\
\mathrm{d} 7 \AA\end{array}$ & $\begin{array}{c}\text { Prop } \\
\mathrm{d} 7^{\#}\end{array}$ & $\begin{array}{c}\text { Ctrl } \\
\mathrm{d} 14\end{array}$ & $\begin{array}{c}\text { Prop } \\
\mathrm{d} 14\end{array}$ & $\begin{array}{c}\text { Ctrl } \\
\mathrm{d} 21\end{array}$ & $\begin{array}{c}\text { Prop } \\
\mathrm{d} 21\end{array}$ \\
\hline Number of values & 54 & 54 & 54 & 54 & 54 & 54 \\
Minimum & 2.818 & 2.776 & 1.248 & 5.875 & 5.245 & 1.587 \\
25\% Percentile & 5.919 & 5.752 & 7.028 & 9.943 & 11.58 & 4.036 \\
Median & 9.585 & 8.357 & 9.849 & 11.85 & 16.59 & 7.746 \\
75\% Percentile & 17.61 & 11.72 & 12.82 & 15.22 & 23.13 & 11.46 \\
Maximum & 38.16 & 37.49 & 19.19 & 28.33 & 76.15 & 26.05 \\
Mean & 12.14 & 10.62 & 9.978 & 13.22 & 20.77 & 8.313 \\
Std. Deviation & 7.966 & 7.940 & 3.838 & 5.063 & 14.58 & 5.248 \\
Std. Error & 1.084 & 1.081 & 0.522 & 0.689 & 1.984 & 0.714 \\
Lower 95\% CI & 9.964 & 8.452 & 8.931 & 11.83 & 16.79 & 6.881 \\
Upper 95\% CI & 14.31 & 12.79 & 11.03 & 14.60 & 24.75 & 9.746 \\
\hline
\end{tabular}

$\S$ Ctrl: control group; \#: Prop: propranolol group.

\section{Collagen density}

Propranolol was effective in impairing deposition of collagen type I fibers into capsule tissue surrounding silicone implants ( $p$-value $<0.0001$, one-way ANOVA, Kruskal-Wallis test) when compared to control group (Figure 5).In the initial phase of the capsular formation ( $7^{\text {th }}$ day) the presence of collagen type I (reddish) was almost the same for all groups. Density of capsular collagen type III is illustrated in Figure 6.

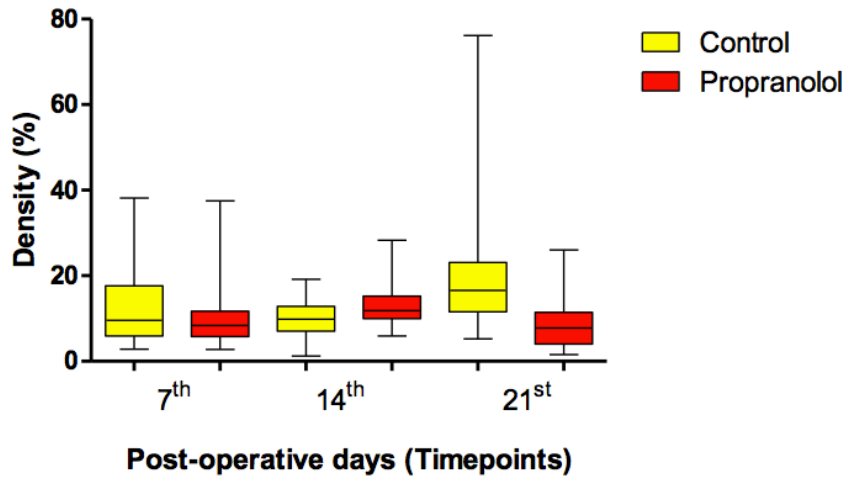

FIGURE 5 - Density of capsular collagen type I Boxes represent control and propranalol groups at $7^{\text {th }}, 14^{\text {th }}$ and $21^{\text {st }}$ timepoints. Significant differences were encountered on $14^{\text {th }}(p<0.001)$ and $21^{\text {st }}$ timepoints $(\mathrm{p}<0.0001)$, when comparing control and propranalol groups.ANOVA test.

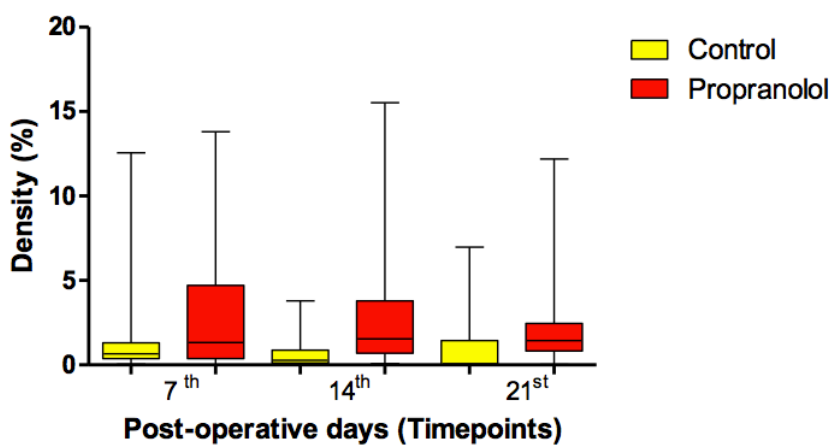

FIGURE 6 - Density of capsular collagen type III Boxes represent control and propranalol groups at $7^{\text {th }}, 14^{\text {th }}$ and $21^{\text {st }}$ timepoints. No significant differences were encountered when comparing timepoints.

There was a trend to increasing collagen type I/type III ratios along the time in control group while in propranololtreated group these ratios exhibited lower and almost constant values along the time. was higher in control group. Proportionally, with the evolution of the post-operatory period, type I collagen increased, and was present in both groups (Figure 7). The highest proportion of type III collagen in propranolol-treated group was of statistical significance at all time-points when both groups were compared; also it was significant into each group comparison.

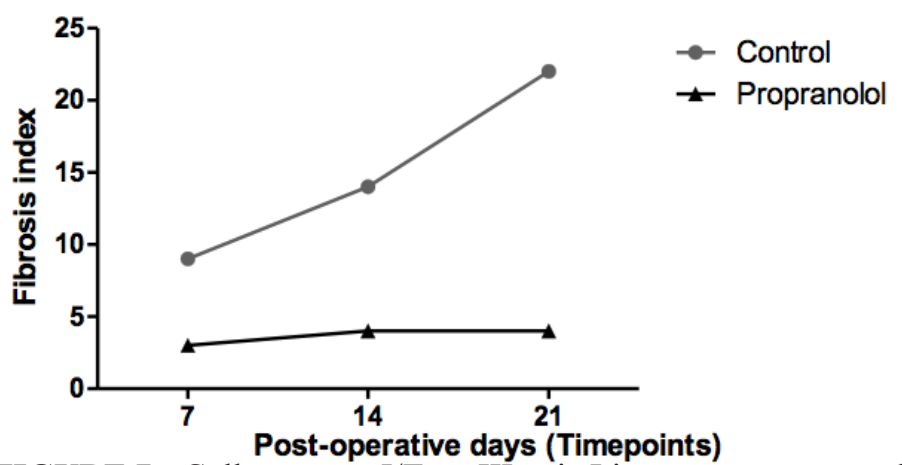

FIGURE 7 - Collagen type I/Type III ratio Lines represent control and propranolol groups at $7^{\text {th }}, 14^{\text {th }}$ and $21^{\text {st }}$ timepoints. 
Figure 8 depicts significant picrosirius red-stained images with and without polarization at $7^{\text {th }}, 14^{\text {th }}$ and $21^{\text {st }}$ timepoints.

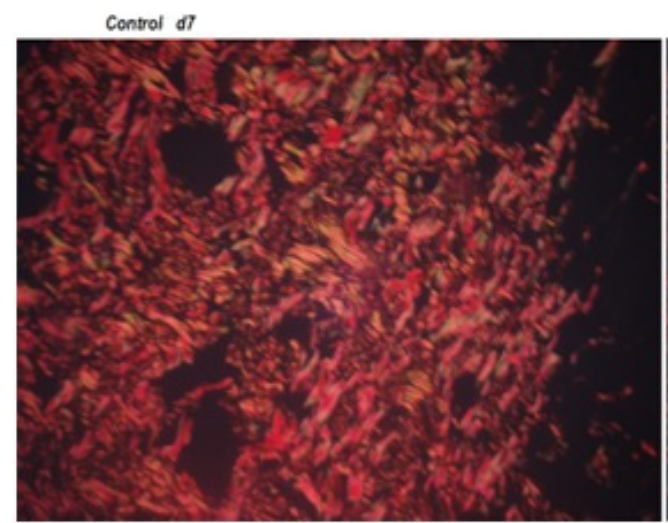

Control $\mathbf{d 1 4}$

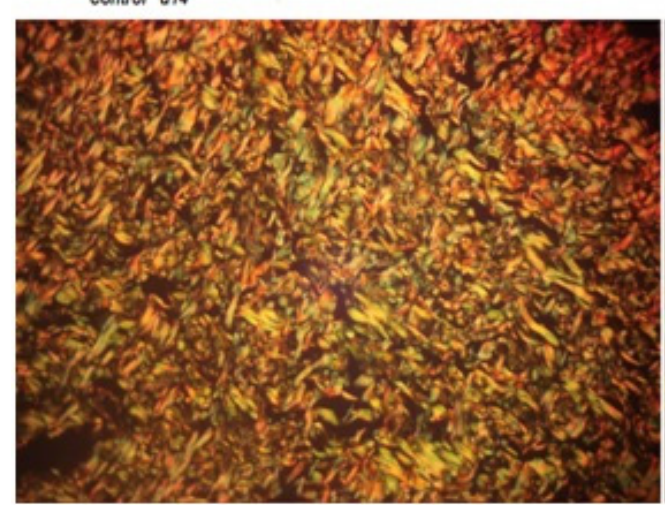

Control 21d

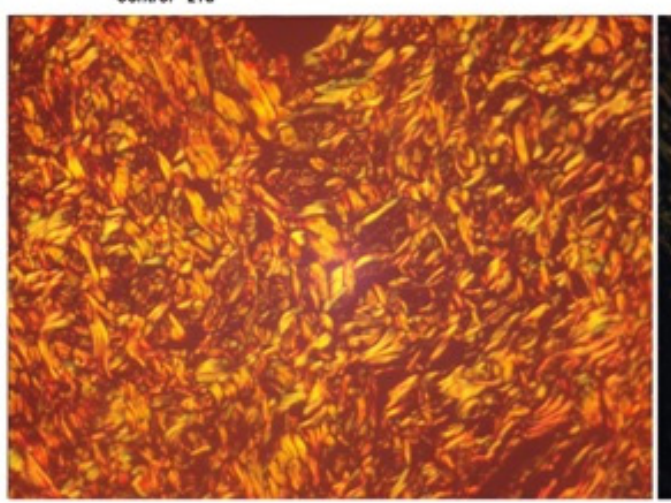

Propranolol d7

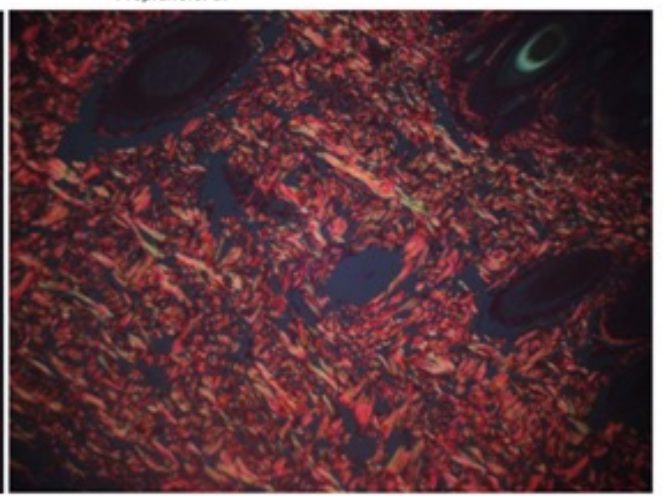

Propranolol d14

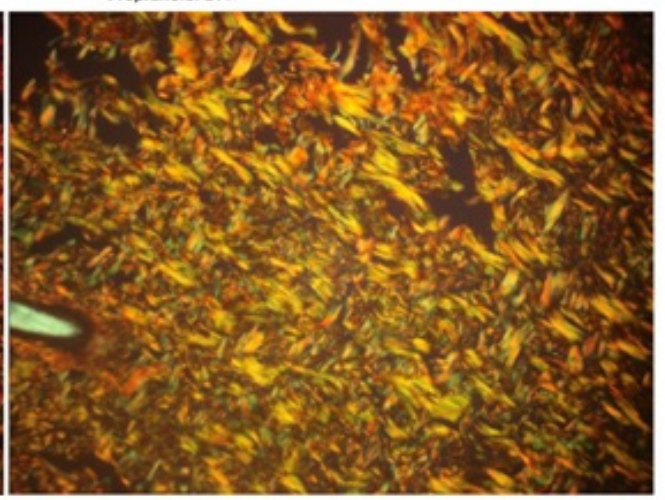

Propranoiol 21d

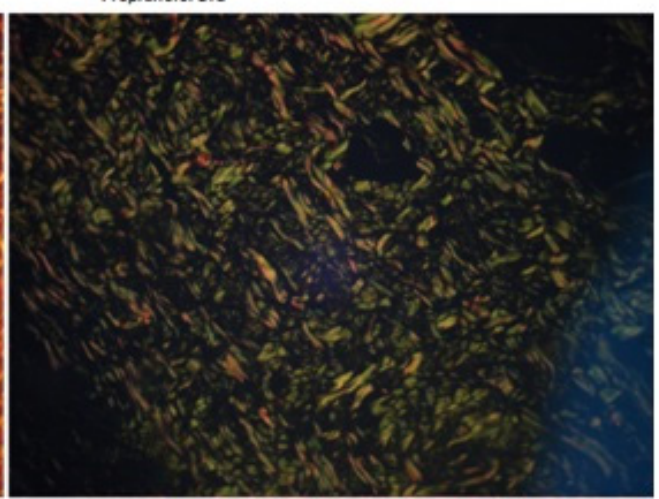

FIGURE 8 - Photomicrography of capsules obtained from propranolol-treated animals (right) or untreated (left) and stained with Sirius Red under polarization. Collagen type I fibers stain reddish (orange or red). Collagen type III stain greenish (x100).

\section{Discussion}

Adverse capsular contracture (ACC) should be regarded as an exaggeration of normal wound healing ${ }^{6}$. In patient populations, this condition is accompanied by overt symptoms and loss of esthetic results of breast augmentation ${ }^{13}$ Since the first reports on capsular contracture in the literature, a number of preclinical studies have been conducted in an attempt to prevent its development, using different drugs (such as leukotriene receptor antagonists, antibiotics, anti-neoplastic and antifibroticagents, steroids and non-steroidal anti-inflammatory drugs) administered locally or systemically, but with disappointing results ${ }^{3-9,13-16}$. Thus, there is currently no proven pharmacological therapy for $\mathrm{ACC}^{13}$.

Special attention should be paid to the possibility of identifying an oral drug for the treatment of a complication that has serious physical, psychological and financial consequences and for which the only effective treatment is surgery. Propranolol is commonly used in the treatment of cardiovascular diseases ${ }^{19}$. Also, propranolol is an effective, well-tolerated and safe first-line treatment for proliferative hemangioma ${ }^{20-21}$. It is a non-selective 
competitive antagonist of beta- 1 and beta-2 adrenergic receptors ${ }^{19-21}$. Epinephrine or norepinephrine adrenoceptors, stress-released catecholamines, have been implicated in the pathophysiology of delayed wound healing of cutaneous lesions, acting by delaying the migration and activation of macrophages and neutrophils, inhibiting keratinocyte migration and re-epithelialization in vitro and in vivo wound models ${ }^{22-23}$. Besides alteration of cellular activity related to inflammation, catecholamines stimulate vasoconstriction that causes hypoxia at the wound area and the increase of endothelial cell proliferation, vascular endothelial growth factor (VEGF) expression and angiogenesis. Also, catecholamines promote inhibition of eosinophil influx ${ }^{23-24}$ High concentrations of catecholamines may delay fibroblasts proliferation, myofibroblastic differentiation and collagen deposition ${ }^{24-26}$. Strack et al. ${ }^{25}$ demonstrated that propranolol was effective in reducing inflammation and liver fibrosis progression in a model of nonsinusoidal fibrosis. The transcript level of profibrogenic cytokines TNF-alfa, TGF-beta and CTGF was reduced $>50 \%$ in fibrotic portal areas. Also, propranolol treatment results in levels of proinflammatory mediators (angiotensinogen and endothelin-1) of vasoconstriction under sympathetic nervous system control.

In this study, the option for silicone instead of saline prostheses was due to the greater incidence of capsular contracture found in the use of the former ${ }^{27}$. PubMed database was extensively searched for reviewing models of capsular contracture. Capsular contracture is a refractory human-specific condition, such as keloids are. The proposed models found have provided valuable information about pathogenesis and treatment possibilities of ACC. The length of the observation time (three weeks) used in this study was based on other studies dealing with wound healing. As for the method of measuring the thickness of the capsule and the collagen type I and type III deposition, the picrosirius polarization microscopy method plus digital measurement, previously described in another context was utilized ${ }^{28-31}$. The use of conventional histology method to assess inflammation was necessary because it remains the most utilized method to assess capsular inflammation ${ }^{32-37}$. Baker's classification and applanation tonometry did not seem very appropriate to investigate contractures or fibrosis in rodent models ${ }^{16-17}$. Nowadays, the use of implants with smooth surfaces is no longer acceptable due to the fact that they behave differently regarding the occurrence of capsular contracture $^{11}$ Therefore, it was decided to use one type of textured prostheses so that responses to the use of propranolol could be verified efficiently without excessive number of variables. In this study, all samples from both groups exhibited a tri-layered capsule as described elsewhere by several scholars in human capsules and animal capsules surrounding textured implants ${ }^{11,33-37}$. Various authors mention that synovial-like metaplasia present in the interface capsule-textured implant is due to mechanic friction between implanted materiel and the peri-prosthetic tissue ${ }^{37-39}$. The tissue invasion of STM directed to the coating texture (aka, villous hyperplasia) was found in all capsules examined, although without significant difference between groups. Despite these fact, propranolol was capable of reduce the thickness of capsular reaction tissue at all timepoints, suggesting an anti-proliferative or cytotoxic effect of the drug.

Lyras $^{40}$, analyzing the tissue reaction to rough and smooth silicone implants in a rodent model detected intense acute inflammatory reaction to textured implants. Here, in nonpropranolol-treated group, this kind of reaction was absent or discrete in $1 / 3$ of capsules at $7^{\text {th }}$ post-operative (PO) day, 2/3 at $14^{\text {th }} \mathrm{PO}$ day and $5 / 6$ at $21^{\text {st }} \mathrm{PO}$ day, confirming the findings already described for textured surface ${ }^{41-43}$. In our study we was found that in propranolol-treated capsules the acute inflammatory reaction was absent or discrete in $1 / 3,5 / 6$ and $2 / 3$ at $7^{\text {th }}, 14^{\text {th }}$ and $21^{\text {st }}$ post-operative day, whereas in control group this reaction was moderate or intense in $2 / 3,1 / 3$ and $1 / 6$ at the same periods. As to chronic inflammatory reaction, in control group this reaction was moderate or intense in $1 / 3$ at $7^{\text {th }} \mathrm{PO}$ day, $1 / 6$ at $14^{\text {th }} \mathrm{PO}$ day and $100 \%$ at $21^{\text {st }}$ PO day, while in propranolol group an absent or discrete chronic inflammatory reaction was found in 5/6,2/3 and $5 / 6$ of the capsules at $7^{\text {th }}, 14^{\text {th }}$ and $21^{\text {st }} \mathrm{PO}$ day respectively. Clearly, propranolol exerted an anti-inflammatory effect that persisted through all the experiment.

The effect of propranolol in reducing capsular inflammation and thickness, and in modulating collagen deposition on textured implants observed in this experiment is consistent with findings from previous studies of others fibrosis conditions $^{19}$, which showed that the application of nonselective beta-adrenoceptors antagonists inhibits maturation of collagen, reduces the number of vessels, collagen density, number of mast cells, eosinophils and myofibroblasts compared with control ${ }^{22,23,25}$. These concerted actions of propranolol provide a new opportunity to support pharmacotherapeutic approaches to human adverse capsular contracture.

\section{Conclusion}

Propranolol reduces the risk of developing capsular fibrosis around silicone implants with textured surface in this guinea pig model. 


\section{References}

1. International Society for Aesthetic Plastic Surgery. Available from http://www.surgery.org

2. Brazilian Society of Plastic Surgery Available from http://www. cirurgiaplastica.org.br.

3. Tang L, Eaton JW. Natural responses to unnatural materials: A molecular mechanism for foreign body reactions. Mol Med. 1999 Jun;5(6):351-8. PMID: 10415159.

4. Thevenot PT, Baker DW, Weng H, Sun MW, Tang L. The pivotal role of fibrocytes and mast cells in mediating fibrotic reactions to biomaterials. Biomaterials. 2011 Nov;32(33):8394-403. doi: 10.1016/j.biomaterials.2011.07.084.

5. Jones KS. Assays on the influence of biomaterials on allogeneic rejection in tissue engineering.Tissue Eng Part B Rev. 2008 Dec;14(4):407-17. doi: 10.1089/ten.teb.2008.0264.

6. Soder BL, Propst JT, Brooks TM, Goodwin RL, Friedman HI, Yost MJ, Gourdie RG. The connexin43 carboxyl-terminal peptide ACT1 modulates the biological response to silicone implants. Plast Reconstr Surg. 2009 May;123(5):1440-51. doi: 10.1097/ PRS.0b013e3181a0741d.

7. Adams WP Jr. Capsular contracture: what is it? What causes it? How can it be prevented and managed? Clin Plast Surg. 2009;36(1):11926. doi: 10.1016/j.cps.2008.08.007.

8. Berry MG, Cucchiara V, Davies DM. Breast augmentation: part II - adverse capsular contracture. J Plast Reconstr Aesth Surg. 2010 Dec;63:2098-107. doi: 10.1016/j.bjps.2010.04.011.b 2010.

9. McCurdy JA, Jr. Capsular contracture following augmentation mammoplasty: etiology and pathogenesis. In: Shifman M (editor). Breast augmentation. Berlin-Heidelberg: Springer; 2009. p.525-40.

10. Barnsley GP, Sigurdson LJ, Barnsley SE. Textured surface breast implants in the prevention of capsular contracture among breast augmentation patients: a meta-analysis of randomized controlled trials. Plast Reconstr Surg. 2006 Jun;117(7):2182-90. PMID: 16772915.

11. Araco A, Caruso R, Araco F, Overton J, Gravante G. Capsular contractures: a systematic review. Plast Reconstr Surg. 2009 Dec;124(6):1808-19. doi: 10.1097/PRS.0b013e3181bf7f26.

12. Embrey M, Adams EE, Cunningham B, Peters W, Young VL, Carlo GL. A review of the literature on the etiology of capsular contracture and a pilot study to determine the outcome of capsular contracture interventions. Aesthetic Plast Surg. 1999 May-Jun;23(3):197-206. PMID: 10384019.

13. Hidalgo DA, Spector JA. Breast augmentation. Plast Reconstr Surg. 2014 Apr;133(4):567e-83e. doi: 10.1097/PRS.0000000000000033.

14. Fernandes JR, Salinas HM, Broelsch GF, McCormack MC, Meppelink AM, Randolph MA, Redmond RW, Austen WG Jr.Prevention of capsular contracture with photochemical tissue passivation. Plast Reconstr Surg. 2014 Mar;133(3):571-7. doi: 10.1097/01.prs.0000438063.31043.79.

15. McCoy BJ, Person P, Cohen IK. Collagen production and types in fibrous capsules around breast implants.Plast Reconstr Surg. 1984 Jun;73(6):924-7. PMID: 6374707.

16. Moreira M, Fagundes DJ, de Jesus Simões M, de Oliveira MC, Dos Santos Previdelli IT, Moreira AC. Zafirlukast pocket delivery impairs the capsule healing around textured implants in rats. Aesthetic Plast Surg. 2009 Jan;33(1):90-7. doi: 10.1007/s00266-008-9245-4.

17. Bastos EM, Neto MS, Alves MT, Garcia EB, Santos RA, Heink T, Pereira JB, Ferreira LM. Histologic analysis of zafirlukast's effect on capsule formation around silicone implants. Aesthetic Plast Surg. 2007 Sep-Oct;31(5):559-65. PMID: 17576504.

18. Scuderi N, Mazzocchi M, Fioramonti P, Palumbo F, Rizzo MI, Monarca C, Onesti MG. Treatment of the capsular contracture around mammary implants: our experience. G Chir. 2008 AugSep;29(8-9):369-72. PMID: 18834572.

19. de Mesquita CJ. About strawberry, crab claws, and the Sir James Black's invention. Hypothesis: can we battle keloids with propranolol? Med Hypotheses. 2010 Feb;74(2):353-9. doi: 10.1016/j.mehy.2009.08.035.

20. Szychta P, Stewart K, Anderson W. Treatment of infantile hemangiomas with propranolol: clinical guidelines. Plast Reconstr Surg. 2014 Apr;133(4):852-62. doi: 10.1097/ PRS.0000000000000007.

21. Amos T, Stein DJ, Ipser JC. Pharmacological interventions for preventing post-traumatic stress disorder (PTSD). Cochrane Database Syst Rev. 2014 Jul 8;7:CD006239. doi: 10.1002/14651858. CD006239.pub2.

22. Souza BR, Cardoso JF, Amadeu TP, Desmoulière A, Costa AM. Sympathetic denervation accelerates wound contraction but delays reepithelialization in rats. Wound Repair Regen. 2005 SepOct;13(5):498-505. PMID: 16176458.

23. Bible LE, Pasupuleti LV, Alzate WD, Gore AV, Song KJ, Sifri ZC, Livingston DH, Mohr AM. Early propranolol administration to severely injured patients can improve bone marrow dysfunction. J Trauma Acute Care Surg. 2014 Jul;77(1):54-60. doi: 10.1097/ TA.0000000000000264.

24. Ellsworth DL, Coady SA, Chen W, Srinivasan SR, Boerwinkle E, Berenson GS. Interactive effects between polymorphisms in the beta-adrenergic receptors and longitudinal changes in obesity. Obes Res. 2005 Mar;13(3):519-26. PMID: 15833937.

25. Strack I, Schulte S, Varnholt H, Schievenbusch S, Töx U, Wendland K, Steffen HM, Drebber U, Dienes HP, Odenthal M. $\beta$-Adrenoceptorblockade in sclerosing cholangitis of Mdr2 knockout mice: antifibroticeffects in a model of nonsinusoidal fibrosis. Lab Invest. $2011 \mathrm{Feb}$;91(2):252-61. doi: 10.1038/labinvest.2010.162.

26. Kisseleva T, Brenner DA. Mechanisms of fibrogenesis. ExpBiol Med (Maywood). 2008 Feb;233(2):109-22. doi: 10.3181/0707-MR-190.

27. Schaub TA, Ahmad J, Rohrich RJ.Capsular contracture with breast implants in the cosmetic patient: saline versus silicone--a systematic review of the literature. Plast Reconstr Surg. 2010 Dec;126(6):21409. doi: 10.1097/PRS.0b013e3181f2b5a2.

28. Mesquita CJG,Leite JAD, Fechine FV, Rocha JLC, Leite JGS, Leite Filho JAD, Barbosa Filho RA. Effect of imiquimod on partial-thickness burns. Burns. 2010;36:97-108. doi: 10.1016/j. burns.2009.04.022.

29. Junqueira LC, Cossermelli W, Brentani R. Differential staining of collagens type I, II and III by Sirius Red and polarization microscopy. Arch Histol Jpn. 1978;41:267-74. PMID: 82432.

30. Junqueira LC, Bignolas G, Brentani RR. Picrosirius staining plus polarization microscopy, a specific method for collagen detection in tissue sections. Histochem J. 1979 Jul;11:447-55. PMID: 91593.

31. Montes GS, Junqueira LC. The use of the picrosirius polarization method for the study of the biopathology of collagen. Mem Inst Oswaldo Cruz. 1991;86(Suppl. 3):1-11. PMID: 1726969.

32. Jamacaru FVF. Quantificação de angiogênese corneana in vivo através de processamento de imagens digitais [Tese]. Universidade Federal do Ceará; 2006.

33. Balderrama CM, Ribas-Filho JM, Malafaia O, Czeczko NG, Dietz UA, Sakamoto DG, Bittencourt LP. Healing reaction to mammary prostheses covered by textured silicone and silicone foam in rats. Acta Cir Bras. 2009 Sep-Oct;24(5):367-76. doi.org/10.1590/S010286502009000500006.

34. Kamel M, Protzner K, Fornasier V, Peters W, Smith D, Ibanez D. The peri-implant breast capsule: An immunophenotypic study of capsules taken at explantation surgery. J Biomed Mater Res. 2001;58(1):88-96. PMID: 20661169. 
35. Bergmann PA, Tamouridis G, Lohmeyer JA, Mauss KL, Becker B, Knobloch J, Mailänder P, Siemers F. The effect of a bacterial contamination on the formation of capsular contracture with polyurethane breast implants in comparison with textured silicone implants: an animal study. J Plast Reconstr Aesthet Surg. 2014 Oct;67(10):1364-70. doi: 10.1016/j.bjps.2014.05.040.

36. Smahel J. Histology of the capsules causing constrictive fibrosis around breast implants. Br J Plast Surg. 1977 Oct;30(4):324-9. PMID: 145256.

37. Ko CY, Ahn CY, Ko J, Chopra W, Shaw WW. Capsular synovial metaplasia as a common response to both textured and smooth implants. Plast Reconstr Surg. 1996 Jun;97(7):1427-35. PMID: 8643727.

38. Haddad Filho D, Zveibel DK, Alonso N, Gemperli R. Comparison between textured silicone implants and those bonded with expanded polytetrafluoroethylene in rats. Acta Cir Bras. 2007 MayJun;22(3):187-94. doi.org/10.1590/S0102-86502007000300006.

39. Brohim RM, Foresman PA, Hildebrandt PK, Rodeheaver GT. Early tissue reaction to textured breast implant surfaces. Ann Plast Surg. 1992 Apr;28(4):354-62. PMID: 1596069.

40. Lyras I. Tissue reaction to rough and smooth silicone implants. A comparative and analytical experimental study in rats. Rev Soc Bras Cir Plast. 1993;8(1):131-41.

41. Clugston PA, Perry LC, Hammond DC, Maxwell GP. A rat model for capsular contracture: the effects of surface texturing. Ann Plast Surg. 1994 Dec;33(6):595-9. PMID: 7880048.

42. Lesesne CB. Textured surface silicone breast implants: histology in the human. Aesthetic Plast Surg. 1997 Mar-Apr;21(2):93-6. PMID: 9143423.

43. Batra M, Bernard S, Picha G. Histologic comparison of breast implant shells with smooth, foam, and pillar microstructuring in a rat model from 1 day to 6 months. Plast Reconstr Surg. 1995 Feb;95(2):354-63. PMID: 7824615.

\section{Acknowledgements}

SILIMED $^{\circledR}$ for donating the mini-implants used in this experiment and Prof. Dr. Marto Leal for his expertise in statistical analysis.

\section{Correspondence:}

Sérgio Botelho Guimarães

Rua Barão de Aratanha, 1465

60050-071 Fortaleza-CE Brasil

Tel.: (55 85)3226-2400

sergiobotelho@terra.com.br

Received: Sep 15, 2014

Review: Nov 17, 2014

Accepted: Dec 18, 2014

Conflict of interest: none

Financial source: none

${ }^{1}$ Research performed at Experimental Surgery Lab (LABEX), Medical Course, Christus Universitary Center (UNICHRISTUS), Fortaleza-CE, Brazil. Part of Master degree thesis, Postgraduate Program in Surgery, Federal University of Ceara (UFC). Tutor: Prof. Dr. José Alberto Dias Leite. 